Article

\title{
Functional Properties of a Cysteine Proteinase from Pineapple Fruit with Improved Resistance to Fungal Pathogens in Arabidopsis thaliana
}

\author{
Wei Wang ${ }^{1,2, \dagger}$, Lu Zhang ${ }^{3, \dagger}$, Ning Guo ${ }^{1, \dagger}$, Xiumei Zhang ${ }^{2}$, Chen Zhang ${ }^{1}$, Guangming Sun ${ }^{2}$ and \\ Jianghui Xie ${ }^{2, *}$
}

1 Anhui Key Laboratory of Plant Genetic \& Breeding, School of Life Science, Anhui Agricultural University, 130 Changjiang West Road, Hefei 230036, China;

E-Mails: wangweisys@ahau.edu.cn (W.W.); guoning@ahau.edu.cn (N.G.); zhangchen@ahau.edu.cn (C.Z.)

2 Key Laboratory of Tropical Fruit Biology, Ministry of Agriculture, Institute of China Southern Subtropical Crop Research, Chinese Academy of Tropical Agricultural Sciences (CATAS), Zhanjiang 524091, Guangzhou, China; E-Mails: xiumeizhang1980@163.com (X.Z.); guangmingsun52@163.com (G.S.)

3 State Key Laboratory of Biocontrol, School of Life Sciences, SunYat-sen University, 510006 Guangzhou, China; E-Mail: luzhangtest@163.com

$\dagger$ These authors contributed equally to this work.

* Author to whom correspondence should be addressed; E-Mail: xjhww@163.com; Tel.: +86-0759-285-9168; Fax: +86-0759-285-8124.

Received: 3 December 2013; in revised form: 19 January 2014 /Accepted: 13 February 2014 / Published: 21 February 2014

\begin{abstract}
In plant cells, many cysteine proteinases (CPs) are synthesized as precursors in the endoplasmic reticulum, and then are subject to post-translational modifications to form the active mature proteinases. They participate in various cellular and physiological functions. Here, AcCP2, a CP from pineapple fruit (Ananas comosus L.) belonging to the C1A subfamily is analyzed based on the molecular modeling and homology alignment. Transcripts of $A c C P 2$ can be detected in the different parts of fruits (particularly outer sarcocarps), and gradually increased during fruit development until maturity. To analyze the substrate specificity of $\mathrm{AcCP} 2$, the recombinant protein was overexpressed and purified from Pichia pastoris. The precursor of purified AcCP2 can be processed to a $25 \mathrm{kDa}$ active form after acid treatment ( $\mathrm{pH} 4.3$ ). Its optimum proteolytic activity to Bz-Phe-Val-Arg-
\end{abstract}


$\mathrm{NH}-\mathrm{Mec}$ is at neutral pH. In addition, the overexpression of AcCP2 gene in Arabidopsis thaliana can improve the resistance to fungal pathogen of Botrytis cinerea. These data indicate that AcCP2 is a multifunctional proteinase, and its expression could cause fruit developmental characteristics of pineapple and resistance responses in transgenic Arabidopsis plants.

Keywords: Ananas comosus; cysteine proteinase; gene expression; proteolytic properties; resistance

\section{Introduction}

Cysteine proteinases (EC 3.4.22, CPs), known as thiol proteinases, are widely distributed among living organisms. CPs in plants mainly participate in key cellular and physiological functions such as development and germination of seeds, leaf and flower senescence, fruit ripening and resistance responses to biotic and abiotic stresses, etc. [1-7]. To date, more than 101 families of CPs were registered in the MEROPS database (last entry from October, 2013) [8]. They are grouped into at least nine clans according to the different folds in the tertiary structure. The best known CP is the papain family (clan CA, family C1). Papain proteinases are synthesized as an inactive precursor with a signal peptide, an N-terminal inhibitory pro-region as well as a mature catalytic domain [9]. Mature papain-like proteinases share similar catalytic residues in the order of Cys....His....Asn/Asp and the three-dimensional structure [10,11]. They are characterized by the presence of multiple disulfide bridges, and mainly accumulate in the vacuole, apoplast or specific vesicles $[12,13]$. There are also differences in the optimum $\mathrm{pH}$ of papain-like CPs owing to the structure and amino acid components [14].

An important source of plant proteinases used in the traditional medicine and industry is bromelain, which is actually a mixture of different CPs with similar amino acid sequences [15-17]. These enzymes display different proteolytic activities and molecular masses ranging from 20 to $38 \mathrm{kDa}$ [18]. However, it is not still clear how these different proteinases within crude bromelain contribute to their functional activity in vivo. Studies to test the potential efficacy of bromelain indicate that at least five distinct AcCPs [stem bromelain (EC 3.4.22.32), acidic stem bromelain, fruit bromelain (EC 3.4.22.33), ananain (EC 3.4.22.31) and comosain] belonging to the papain family could take part in different physiological processes [11,16,17,19]. Several synthetic peptide substrates (such as Z-Arg-Arg-NH-Mec and Bz-Phe-Val-Arg-NH-Mec) had been used to characterize the proteolytic activity of purified bromelain enzymes [19-22]. Until now, more than six major full-length genes of CPs from bromelain complex have been identified in the MEROPS database, which are comprised of stem bromelain and fruit bromelain. By contrast, fruit CP (O23791) and stem CP (ADY68475) share 87\% cDNA sequence identity [22,23]. In stem bromelain, two homology genes named comosain and ananain have been also isolated, but there are no reports of AcCP isoforms of fruit bromelain. Although the physicochemical properties of fruit and stem bromelains are very well characterized [18,20,22,24], their in vivo roles are not yet completely understood, especially in the development and ripening of pineapple fruits. Therefore, the current research mainly focuses on functional properties of a $\mathrm{CP}$ isolated from pineapple fruit library. The expression patterns of $A c C P 2$ in tissues and sugar accumulation are also examined. 
The results reveal that transcription levels of $A c C P 2$ might be correlated to the fruit softness and maturity. Currently, although many approaches have been used to improve the purity and activity of bromelain enzyme preparations, they require expensive materials and complicated processes [15]. Because of the benefits of yeast expression system [25], AcCP2 was expressed in Pichia pastoris to study the detailed enzymatic properties and possible biotechnological application using synthetic substrates in vitro. In addition, transgenic Arabidopsis plants overexpressing the AcCP2 gene demonstrate the improved resistance to fungal pathogens.

\section{Results and Discussion}

\subsection{Molecular Cloning of the AcCP2 Gene}

For isolating the genes related to fruit development and ripening, cDNA libraries of pineapple fruits were constructed into pGEM-T easy vector using mRNAs of different developmental stages. Of these sequences, 12 fragments showed significant identity to CPs of A. comosus. The RACE method was adopted to amplify the full-length genes. Interestingly, a full-length cDNA including an open reading frame of $1059 \mathrm{bp}$ and two untranslated regions (5'-102 bp and 3'-253 bp) was obtained and the gene was $A c C P 2$, the homologous gene of fruit bromelain. The sequence was deposited in GenBank (ID: JF831511). AcCP2 was predicted to contain a signal peptide (SP) preceding the N-terminal sequence (1-24 amino acids), suggesting an extracellular localization. The prosequence residues $24-122$ precede the mature enzyme residues 122-352 (Figure 1A). As could be expected, the predicted AcCP2 protein contains several of characteristic elements of papain structure and active sites (Figure 1A,B), which are essential for catalytic activity and maintaining the tertiary structure [26]. Location and functions of the cis-elements were predicated by PlantCARE database search program. Two highly conserved motifs found in most papain-like CP propeptides, GxNxFxD and ERFNIN seem to be essential for the correct processing of proteinase precursors (Figure 1B) [27]. The sequence of AcCP2 is homologous to CPs from Bromeliaceae, sharing 88\% identity with stem bromelain (ADY68475), and 87\% identity with macrodontain I (P83443). Although the highest homology is found between fruit bromelain (O23791) and $\mathrm{AcCP} 2$, there are some differences in functional domains and length (Figure 1C). In addition, AcCP2 has the lower similarity to other proteinases, $40 \%, 44 \%$ and $47 \%$ identity with papain (P00784), A. thaliana (BAC43602) and Oryza sativa (CAH66275), respectively.

\subsection{Structure Characteristics of the AcCP2 Protein}

$\mathrm{N}$ - and C- terminal domains of CP from different species display conserved characteristics (see multiple sequence alignment in Figure S1A). In overall structure predicted by the template of papain, the mature protein fold is composed of two domains with the catalytic site lying between them. The left (L) domain (N-terminal domain) consists of some helices and active sites of Gln20 and Cys26. The right $(\mathrm{R})$ domain contains His158 and Asn179 residues (Figure S1B). Three disulfide bonds (23-57, 63-96 and 152-204) could play a key role in maintaining the three dimensional structure [13]. Analysis of the phylogenetic tree also clearly shows that AcCP2 belongs to $\mathrm{CA}: \mathrm{C} 1$ family and is more closely related to each other from pineapple stems and fruits than to other members of papain family (Figure S1C). 
Figure 1. Representation of AcCP2 domains and deduced amino acid sequences. (A) Schematic demonstration of AcCP2 structure characteristics; (B) Deduced amino acid sequences of AcCP2. The letters underlined in nucleotide sequences indicate the CAAT box, TATA box and GC box in the upstream of start codon. CA-GU sequences are regarded as an alternative site combining PolyA synthase in higher plants. The consensus polyadenylation signal (AATAAA) is found in 3' UTR. SP, GxNxFxD and ERFNIN motifs are also noted in the propeptide. Conserved active sites (Gln, Cys, His and Asn) are labeled in asterisks (*); and (C) Alignment of amino acid sequences between AcCP1 (O23791) and AcCP2 (AEH26024).

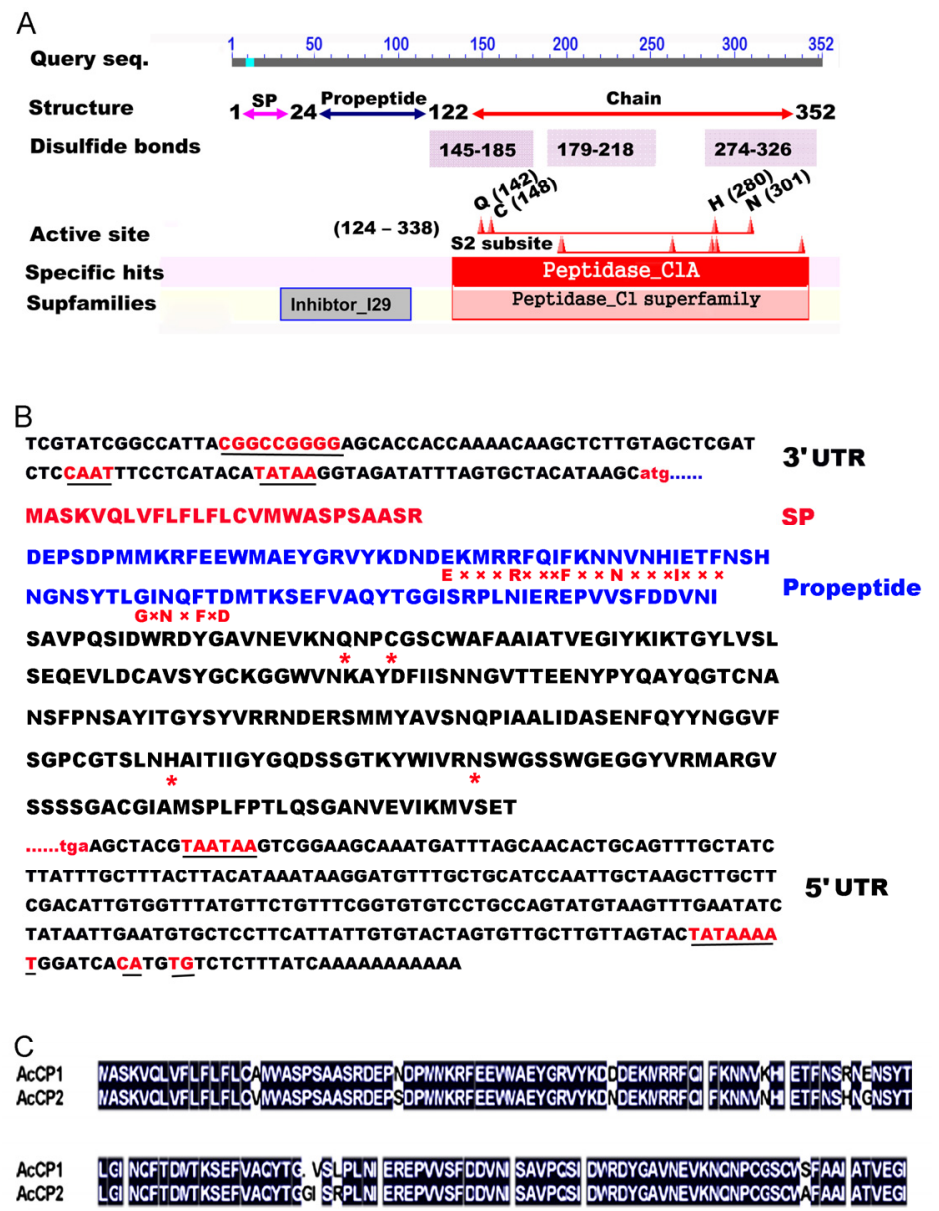

\subsection{Expression Patterns of AcCP2 During Pineapple-Fruit Development}

Although the transcripts of $A c C P 2$ can be detected during development and ripening of pineapple fruits using Northern blot, continuous $A c C P 2$ mRNA differences are found in contrast to expression levels of $\beta$-actin (Figure 2A). As shown in Figure 2B, $A c C P 2$ is strongly expressed in mature fruits, especially in the outer sarcocarps. However, RNAs from leaf and stem show significantly lower hybridization signals. From 20 to 70 days after anthesis, the transcript levels of $A c C P 2 \mathrm{mRNA}$ are gradually increased to 10 -fold in fruit samples. No significant differences are observed between 70 and 80 days. The results suggest that expression of $A c C P 2$ could be involved in the growth and development of pineapple fruits. Fruit bromelain is isolated and analyzed using western blot. A distinct $\approx 25 \mathrm{kDa}$ band can be detected using purified antibodies (Figure 2C). 
Figure 2. Temporal and spatial transcript levels of $A c C P 2$ are analyzed by Northern blotting with specific probe primers. To ensure equal sample abundance on gels, rRNAs are quantified to monitor loading equivalence. $\beta$-Actin gene is used as an internal control. The data is used for analysis from at least three independent experiments $\pm \operatorname{SE}(n=3)$.

(A) The characteristics of $A c C P 2$ transcription during fruit development and ripening; (B) Expression levels of $A c C P 2$ in different tissues of pineapple; and (C) AcCP protein detection in pineapple fruits using purified antibodies.
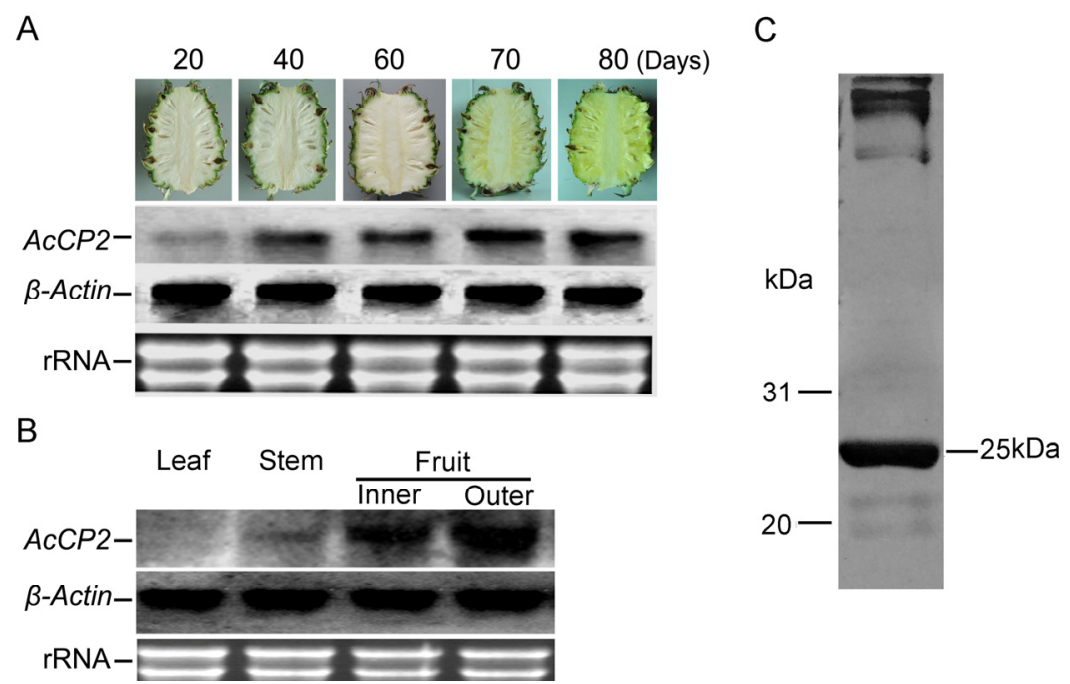

\subsection{Expression of His-AcCP2 Recombinant Protein}

The pPIC9K-AcCP2 plasmids were expressed in $P$. pastoris for exploring the enzymatic properties and possible biotechnological applications of AcCP2. Western blot shows a $\approx 36 \mathrm{kDa}$ protein which corresponds to the protein precursor plus the His6x tag. Regardless of the success of expression of the protein in yeast, the propeptide has to be removed from the protein to be active, even if it is a natural product [28]. AcCP2 protein was purified using Ni-NTA beads, and then treated in acetate buffer at $\mathrm{pH} 4.3$ to induce autoactivation. An approximately $25 \mathrm{kDa}$ single band was demonstrated on the nitrocellulose membrane, whereas unprocessed protein is $\approx 36 \mathrm{kDa}$ (Figure $3 \mathrm{~A}$ ).

\subsection{Catalytic Characteristics of His-AcCP2 Recombinant Protein Using Synthetic Substrates}

To understand the nature of substrates for AcCP2 protein expressed in yeast, catalytic and specific activities were analyzed using Bz-Phe-Val-Arg-NH-Mec and Z-Arg-Arg-NH-Mec. The activities of purified AcCP2 protein and commercial fruit bromelain using equivalent amounts were determined against two synthetic substrates. Two samples also have specific activities against the Bz-Phe-ValArg-NH-Mec substrate, whereas they show minimal activities against Z-Arg-Arg-NH-Mec substrate (Table 1). The purified AcCP2 shows a broad range of activity from $\mathrm{pH} 4.0$ to 10.0 , and has the optimum $\mathrm{pH} \approx 7.0$ using Bz-Phe-Val-Arg-NH-Mec substrate (Figure 3B). However, the proenzyme lacks this hydrolytic activity (data not shown). 
Figure 3. Protein purification and proteolytic activity of AcCP2 expressed in yeast. (A) Immuno-detection of recombinant His-AcCP2 protein. Lane 1: AcCP2 crude proteins extracted from yeast containing the pPIC9K-His-AcCP2 vector; Lane 2: crude proteins extracted from yeast containing the pPIC9K empty vector; Lane 3: protein purification by Ni-NTA beads from yeast containing the pPIC9K-His-AcCP2 vector; Lane 4: the purified protein incubated at $\mathrm{pH} 4.3$; and (B) Activity was measured on 1\% Bz-Phe-Val-Arg-NHMec solution containing $15 \mathrm{mM}$ AcCP2 proteinase under different $\mathrm{pH}$. Data points represent the mean values of three replicates $\pm \mathrm{SE}(n=3)$.
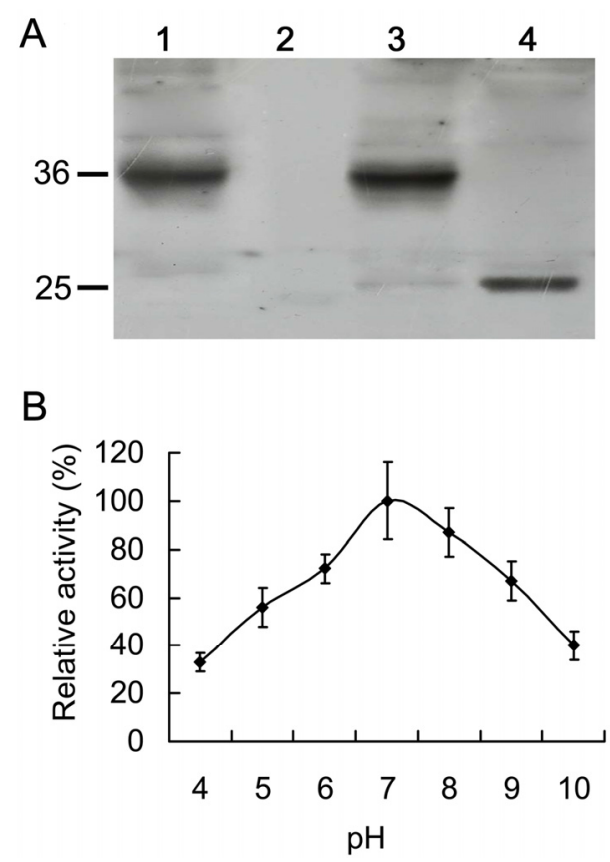

Table 1. Michaelis-Menten constants $\left(K_{m}\right)$ and catalytic rate constants $\left(k_{c a t}\right)$ for purified AcCP2 with Bz-Phe-Val-Arg-NH-Mec and Z-Arg-Arg-NH-Mec substrates. Data represent the mean values of three replicates $\pm \mathrm{SE}(n=3)$.

\begin{tabular}{clccc}
\hline Proteinase & \multicolumn{1}{c}{ Substrates } & $\boldsymbol{K}_{\mathrm{m}}(\boldsymbol{\mu M})$ & $\boldsymbol{k}_{\text {cat }}\left(\mathbf{S}^{-1}\right)$ & $\boldsymbol{k}_{\text {cat }} / \boldsymbol{K}_{\mathrm{m}}\left(\mathbf{M m}^{-\mathbf{1}} \cdot \mathbf{S}^{-\mathbf{1}}\right)$ \\
\hline AcCP2 $^{\mathrm{a}}$ & Z-Arg-Arg-NH-Mec & $72.3 \pm 6.4$ & $0.004 \pm 0.001$ & 0.005 \\
& Bz-Phe-Val-Arg-NH-Mec & $3.2 \pm 1.1$ & $15.4 \pm 4.8$ & 4812.5 \\
Commercial $^{\text {B }}$ & Z-Arg-Arg-NH-Mec & $82.5 \pm 10.2$ & $0.003 \pm 0.001$ & 0.003 \\
bromelain $^{\text {b }}$ & Bz-Phe-Val-Arg-NH-Mec & $4.6 \pm 1.0$ & $14.12 \pm 5.2$ & 3065 \\
\hline
\end{tabular}

${ }^{\mathrm{a}}$ His-AcCP2 recombinant protein purified from yeast and incubated with $\mathrm{pH} 4.3$ buffer; ${ }^{\mathrm{b}}$ Commercial bromelain preparations obtained from fresh pineapple fruit predominantly.

\subsection{Disease Resistance Analysis in Transgenic Arabidopsis Plants}

In our study, Arabidopsis is used as a heterologous expression system to test whether overexpression of $A c C P 2$ is important to inhibit the infection of fungal pathogens. Seven transgenic T0 seedlings with kanamycin-resistant phenotype were grown until flowering for T1 seed set. RT-PCR analysis shows a corresponding band to $A c C P 2$ in all transgenic T1 seedlings, but not in the control (Figure 4A). $X^{2}$ test of $\mathrm{T} 1$ seeds indicates that most transgenic lines contain one or more copies of insert genes in their genomes (data not shown). These data, thus, demonstrate $A c C P 2$ is successfully 
expressed in these transgenic Arabidopsis plants. And then, B. cinerea is selected to infect the transgenic lines to detect the resistance to fungal pathogen. Interestingly, severe disease symptoms appear on wild-type plants 6 days after inoculation, whereas these transgenic lines show much weaker symptoms by evaluation of necrosis sizes (Figure 4B). Immune blot analysis reveals that transgenic plants express an expected $25 \mathrm{kDa}$ protein, which cannot be detected in wild-type (Clo-0) plants (Figure 4C). Though the mechanism of resistance increase has not been understood, it is clear that the constitutive expression of $A c C P 2$ from pineapple fruits in Arabidopsis can enhance resistance to B. cinerea.

Figure 4. Disease resistance to fungal pathogen in transgenic Arabidopsis plants overexpressing AcCP2. (A) Detection of transgenic Arabidopsis plants using RT-PCR. Actin was used as an internal control; (B) Disease degree was showed on the leaves of wild-type (Col-0) and transgenic Arabidopsis plants 2, 4 and 6 days after inoculation; and (C) Western blotting analysis for AcCP2 protein in transgenic Arabidopsis plants. Ribulose is used as a control.
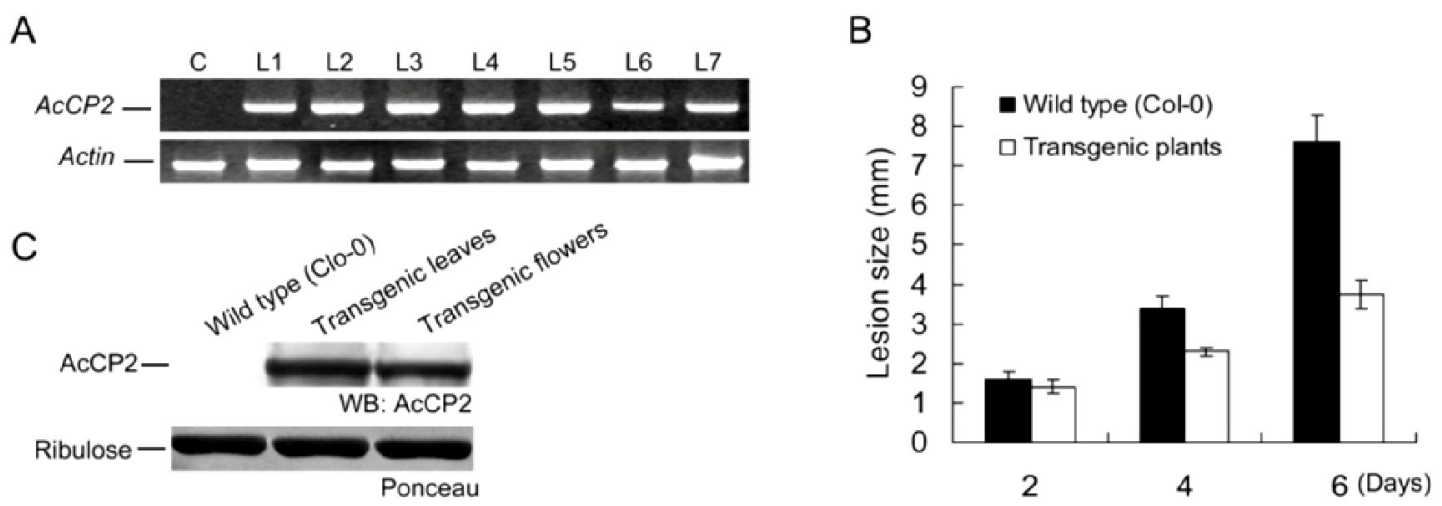

\subsection{Discussion}

In the present study, an $A c C P 2$ encoding $\mathrm{CP}$ had been isolated by screening cDNA library of pineapple fruit, which is the sub-family $\mathrm{C} 1 \mathrm{~A}$ of papain-like CPs with sequence similarities (Figure S1C). It is synthesized as inactive pre-proenzymes with a signal peptide and a multifunctional $\mathrm{N}$-terminal proregion proved by the analysis of catalytic activity (Figure 3). The N-terminal region plays an important role not only as inhibitors of enzymatic activity but for the correct folding of newly synthesized protein [12]. Furthermore, it could protect the protein against denaturing effects in sudden changes of $\mathrm{pH}$ conditions [12,20]. By contrast, AcCP2 also contains ERFNIN and GxNxFxD sequences (Figure 1B) like other members of $\mathrm{C} 1 \mathrm{~A}$ sub-family, which is thought to inhibit protein activity and should be removed before converting to the enzymatically active form $[27,29,30]$. This was evidenced that mature enzyme can be produced by mediating $\mathrm{pH}$ value of reaction buffer and cleaving the pre-sequence of AcCP2 proenzyme (Figure 2A). However, some papain subfamilies lack or contain only part of this sequence, resulting in a shorter proregion such as in cathepsin B [14]. Based on the predicted three-dimensional structure of AcCP2 (Figure S1B), Cys26 known as nucleophile, could be activated by His158 in the active sites [31]. Besides Cys26 and His158, Gln20 could help to form the electrophilic center that stabilizes the tetrahedral intermediate, while Asn179 is 
thought to orientate the imidazolium ring of catalytic His158 [29,32]. A single amino (cathepsin L5/L69Y) acid substitution can substantially influence the architecture of S2 subsite of Fasciola hepatica cathepsin L proteinases [33]. Therefore, we speculate that the active site of Cys 26 is supplemented by Asn 179 hydrogen bonding to His 158 .

In the papain family, CPs demonstrate different catalytic activities to various substrates, including endopeptidases (cathepsins B, H, L and C), aminopeptidase (cathepsins $\mathrm{H}$ and $\mathrm{C}$ ) and carboxipeptedase activity (cathepsin C) [34]. Fruit bromelain has also shown different activity to various protein substrates following different optimum $\mathrm{pH}$ and temperatures, such as at $\mathrm{pH} 7.7$ for casein $\left(59^{\circ} \mathrm{C}\right)$ and at 6.5 for azocasein $\left(55^{\circ} \mathrm{C}\right)$ [22]. We found that $\mathrm{AcCP} 2$ purified from yeast had a high proteolytic activity against Bz-Phe-Val-Arg-NH-Mec, not for Z-Arg-Arg-NH-Mec (Table 1). However, AcCP2 peptidase precursor expressed in yeast lacks the proteolytic activity to Bz-Phe-ValArg-NH-Mec. That is because most heterologous expression systems for CPs produce proteolytically inactive proenzymes, which are stable at slightly acidic to slightly alkaline $\mathrm{pH}$ values [28]. Interestingly, the propeptide region of $\mathrm{AcCP} 2$ can be removed autocatalytically in vitro after incubation into acetate buffer ( $\mathrm{pH} 4.3$ ). However, other exopeptidases require an additional proteinase for full activation such as cathepsins $\mathrm{X}$ and $\mathrm{C}$ [35]. AcCP2 transcripts can be detected in different development stages of pineapple fruits, which are consistent with the microarray analysis of gene expression profiles during fruit ripening [36], especially in outer sarcocarp. Although the reason and mechanism are not clear, plant proteinases are responsible for mediating a fundamental network of protein metabolism pathways during a life cycle [26,37]. In pineapple fruits, to keep the balance of sucrose-sink during fruit growth and development, invertases catalyze the irreversible hydrolysis of sucrose to glucose and fructose. From 40 to 80 days after anthesis, the ratio of hexose and sucrose is gradually decreasing with increase of the transcription levels of $A c C P 2$ (Figure S2A-B). However, the activity of invertase located in the vacuole is dramatically regulated to a negligible level (Figure S2C), especially in the core and basal sections [38]. In tomato, a CP has a dual function to regulate the gene expression of 1-aminocyclopropane-1-carboxylic acid synthase, which can affect the production of ethylene [39]. AcCPs synthesized in the ER as inactive precursors can be converted into the active forms by self-catalytic activity under acidic conditions, which implies that AcCPs maturation could take place in the vacuole. Therefore, these data together suggest the role of AsCP2 might regulate the level of acid invertase, or participate in alternating the cell wall texture during softening through protein metabolism based on the consistent tendency between AsCP2 transcript characteristics and invertase abundance. Yamada et al. also found that CP was responsible for the maturity and activation of vacuole hydrolytic enzymes, which were involved in the degradation of cellular components sequestered from the cytosol by autophagy [40]. Plant CPs also participate in response to adverse environmental stresses, and possess remarkable toxicity against pathogens [4,41-43]. The classic examples demonstrated that papain or papain-like enzymes in the latex of papaya and fig (Ficus virgata) inhibited the growth of lepidopteran larvae [41]. We also found that overexpression of AcCP2 in transgenic Arabidopsis plants improved disease resistance to B. cinerea (Figure 5B). Similar defense responses to pests and pathogens had been observed in other plants expressing $C P$ genes $[2,4,42,44,45]$. Expression levels of AcCYS1 (A. comusus cystatin 1, an endogenous inhibitor of bromelain) are directly related with the resistance to blackheart in pineapple fruits, which implies that CP takes part in the defense response [43]. Increase of CP activity can enhance the degradation of 
gelatin-based jellies in vitro or the processing of a class IV chitinase in planta [46]. Whatever the mechanism is, our results indicate that $A c C P 2$ can be utilized for protecting plants from attack by fungal pathogens. In the future, further investigation is required to elucidate the interaction between $\mathrm{CP}$ and other proteins involved in the defense system.

\section{Experimental}

\subsection{Plant Materials}

Pineapple fruits (Ananas comosus cv. Comte de Paris) were selected from an orchard of the South Subtropical Crop Research Institute (SSCRI), Zhanjiang, Guangdong, China. The experimental materials used in this study were under the same management conditions such as irrigation, fertilization, soil management, disease control and pruning. Fifteen uniform fruits were randomly sampled every ten days throughout fruit development periods from the 20th day after anthesis between May and July in 2009. These fruits were immediately frozen in liquid nitrogen after sampling and stored at $-80^{\circ} \mathrm{C}$. The sliced fleshes of five fruits were pooled together as one of three replications at each harvesting time. Seeds of Arabidopsis thaliana ecotype Columbia were surface-sterilized and allowed to germinate on agar plates $(0.8 \%)$ [47]. The seedlings were transferred to soil 6 days after germination, and placed in a growth chamber at $22{ }^{\circ} \mathrm{C}$ under a $12 \mathrm{~h}$ light-dark cycle.

\subsection{Isolation of AcCP2 Gene}

By screening the cDNA libraries of pineapple fruits, a fragment with a polyA tail and 3'-untranslated region (UTR) showed high homology to CP. The 5'-full RACE kit (Takara, Dalian, China) was used to obtain its potential protein-coding region. Total RNA was extracted from pineapple fruits using Trizol Reagent (Invitrogen, Carlsbed, CA, USA). Poly(A) ${ }^{+}$mRNA was isolated using the mRNA isolate kit (Omega, Norcross, GA, USA), and was transcribed into a single stranded cDNA according to the instruction of cDNA synthesis kit (Takara). Following the manufacturer's protocol of 5' RACE kit (Clontech, Mountain View, CA, USA), $2 \mu \mathrm{L}$ of cDNA was used as a template to amplify the 5'-terminal sequence using nested PCR primers (GSP1 and GSP2 for 5' RACE, Table S1). Finally, the PCR production was cloned into the pGEM-T Easy vector (Promega, Madison, WI, USA) for sequencing.

\subsection{Extraction and Purification of Plant Proteins}

Fruit proteinases were extracted from fresh pineapple (immature and mature) as described by Neuteboom et al. [27]. The major component proteinases within bromelain were separated by ammonium sulfate precipitation, dialysis and cationic exchange chromatography [19]. The bicinchoninic acid assay (Pierce Chemical, Rockford, IL, USA) was used to measure protein concentration.

Arabidopsis tissues were collected with forceps in $1.5 \mathrm{~mL}$ Eppendorf tubes containing $100 \mu \mathrm{L} 2 \times$ buffer [SDS/sample buffer, $125 \mathrm{mM}$ Tris- $\mathrm{HCl} \mathrm{pH}$ 6.8, 4\% (w/v) SDS, 20\% (v/v) glycerol, 2\% (v/v) $\beta$-mercaptoethanol, $0.001 \%(\mathrm{w} / \mathrm{v})$ bromophenol blue]. Plant materials were ground using a drill with a pestle-like bit in the Eppendorf tube until the mixture was homogeneous and immediately transferred 
to ice. All the extracts were resolubilized in the SDS buffer under the room temperature $\left(20^{\circ} \mathrm{C}\right)$, and were centrifuged at maximum speed (10 min, 13,000 g) to save the supernatant.

\subsection{RNA Blot Analysis}

Temporal and spatial expressions of $A c C P 2$ gene in pineapple fruits were measured using Northern blotting. Specific probes were produced by PCR amplification (Table S1, $A c C P-\mathrm{F} 1 \mathrm{~b}$ and $A c C P$-R $1 \mathrm{~b}$ ) according to the manufacturer's instruction of a DIG-labeled cDNA probe kit (Roche Diagnostics, Mannheim, Germany). Actin (HQ148720) probes were added as an internal control. The signals were detected using CDP-StarTM detection reagent (Amersham Biosciences, Bucks, UK) and following exposure to X-ray film.

\subsection{Expression and Purification of pPIC9K-AcCP2 in P. pastoris}

To obtain the expression production of recombinants in P. pastoris, cDNA coding the AcCP2 protein was amplified using CP-F2c and CP-R2c primers (Table S1). The PCR production was digested with Not I as well as EcoR I, and then was ligated into pPIC9K vector. The recombinants were transformed into competent yeast cells (in P. pastoris strain GS115) and selection of $\mathrm{Mut}^{+}$ transformants was performed according to the Pichia Expression System Manual (Invitrogen, California, CA, USA). Recombinant plasmids of candidate clones were extracted by the Yeast Plasmid kit (Omega), and were tested by plasmid PCR using above primes. $300 \mu \mathrm{L}$ of nickel-nitrilotriacetic acid (Ni-NTA) resin beads (Qiagen, Hilden, Germany) were mixed with the extracted proteins and gently stirred on a shaker at $150 \mathrm{rpm}$ for $30 \mathrm{~min}$. The mixture was washed with 3 volume of buffer (100 mM NaH${ }_{2} \mathrm{PO}_{4}, 10 \mathrm{mM}$ Tris/HCl $\mathrm{pH}$ 6.8, $8 \mathrm{M}$ Urea, $\mathrm{pH}$ 6.3). Finally, proteins were eluted with 1 $\mathrm{mL}$ of elution buffer $\left(100 \mathrm{mM} \mathrm{NaH}_{2} \mathrm{PO}_{4}, 10 \mathrm{mM}\right.$ Tris/HCl pH 6.8, $8 \mathrm{M}$ Urea $\left.\mathrm{pH} 4.5\right)$.

\subsection{Antibodies and Western Blots}

The constructed plasmids carrying pET30-AcCP2 were expressed in Escherichia coli BL21 (DE3) cells. After incubation with $0.4 \mathrm{mM}$ isopropyl- $\beta$-d-thiogalactopyranoside at $18{ }^{\circ} \mathrm{C}$ for $24 \mathrm{~h}$, His-tagged AcCP2 protein was purified by nickel affinity chromatography according to the manufacturer's protocol (Qiagen, Valencia, CA, USA). The protease factor Xa was used to remove the His tag from purified AcCP2 based on the supplier's recommendations (New England Biolabs, Ipswich, MA, USA). The isolated protein was used for immunization of a New Zealand rabbit. For immune detection, recombinant proteins expressed in yeast were resolved by SDS-PAGE $(12 \% \mathrm{w} / \mathrm{v})$ and transferred onto a nitrocellulose membrane (Schleicher \& Schuell BioScience, Dassel, Germany) by electroblotting (200 mA for $2 \mathrm{~h}$, at $4{ }^{\circ} \mathrm{C}$ ). Gels were stained either with Coomassie Brilliant Blue R-250 [48]. The membrane was subjected to immunodetection using secondary antibodies conjugated with a horseradish peroxidase (HRP)-conjugated goat anti-rabbit IgG antiserum (Boster, Wuhan, China). Immune blots were developed with a 3,3'-diamino-benzidine (Boster) as the chromogen. 


\subsection{Enzymatic Activity of Recombinant Proteinase}

The proenzyme autocatalytic activation was assayed by incubating the purified proteins with various buffers after $1 \mathrm{~h}$ at $37{ }^{\circ} \mathrm{C}$ [9]. Catalytic activity was measured using the synthetic peptide substrates, Z-Arg-Arg-NH-Mec and Bz-Phe-Val-Arg-NH-Mec purchased from Sigma-Aldrich (St Louis, MO, USA), at $250 \mu \mathrm{g} \cdot \mathrm{mL}^{-1}$ final concentration [20]. Peptidyl-NH-Mec substrate cleaved by proteinases can be detected colorimetrically at $410 \mathrm{~nm}$ in reaction buffer $(10 \%$ dimethylformamide, $5 \mathrm{mM}$ cysteine, $5 \mathrm{mM}$ EDTA, and 0.1 M HEPES pH 7.3). Absorbance was measured at $30 \mathrm{~s}$ intervals for $20 \mathrm{~min}$ using a spectrophotometer (Shimadzu, Kyoto, Japan). The equivalent protein concentrations measured as above description were calculated from standards of known concentration in each assay.

The effect of $\mathrm{pH}$ on the enzymatic activity of the recombinant AsCP2 protein was investigated on 1\% Bz-Phe-Val-Arg-NH-Mec substrate solution containing $15 \mathrm{mM} \mathrm{CPs}$ within the $\mathrm{pH}$ range 4.0-10 using citrate phosphate buffer $(\mathrm{pH} 3.0-7.0)$, Tris- $\mathrm{HCl}$ buffer $(\mathrm{pH}$ 8.0-9.0) and glycine-NaOH buffer (pH 8.0-11.0) with a constant temperature of $37^{\circ} \mathrm{C}$ [49].

\subsection{Measurement of Sugar Contents and Invertase Activity in Pineapple Fruits}

The contents of glucose, fructose and sucrose were analyzed by high-performance liquid chromatography (HPLC, Shimadzu LC-6A; Kyoto, Japan), which was equipped with a RI detector and a SP1010 column (Showa Denko KK, Tokyo, Japan). The mobile phase was acetonitrile/water $(75 \% / 25 \%)$ at a flow rate of $0.5 \mathrm{~mL} \cdot \mathrm{min}^{-1}$. Invertase activity was extracted and assayed as described previously [38]. All assays were performed in triplicate and 30 fruits were used for each replicate.

\subsection{Agrobacterium-Mediated Floral Dip Transformation of Arabidopsis}

The full-length $A c C P 2$ cDNA in recombinant pGEM-T easy vector was amplified with the following AcCP-F2c and AcCP-R2c primers (Table S1) containing two introduced BamH I and Xba I restriction enzyme sites, respectively. The fragment was cloned into pCAMBIA1305 containing 35S promoter from pRT104 vector digested with the same enzyme digestion. pCAMBIA1305:35S:AcCP2 recombinant plasmids were transformed into Agrobacterium tumefaciens (strain EHA105) competent cells via electroporation $(1800 \mathrm{~V})$ according to the protocol supplied by the manufacturer (Bio-Rad). Transformation was accomplished by simply dipping Arabidopsis inflorescences by Agrobacterium cells carrying the recombinants [47]. About 30 ng of genomic DNAs extracted using CTAB method [50] were used for PCR amplification with the primers (Table S1) in order to confirm the putative transgenic Arabidopsis plants.

\subsection{Treatment of Arabidopsis Plants}

For the whole-plant infection, three to four fully expanded leaves per plant were inoculated by spraying with a spore suspension of $B$. cinerea $\left(5 \times 10^{5}\right.$ conidiospores $\mathrm{ml}^{-1}$ in $24 \mathrm{~g} \mathrm{~L}^{-1}$ potato dextrose broth, Difco, Detroit, ML, USA). Inoculated plants were placed in a growth chamber at $22{ }^{\circ} \mathrm{C}$ under a $12 \mathrm{~h}$ light-dark cycle. Relative humidity was maintained at $100 \%$ by covering the plants with clear plastic. Control plants were treated with only potato dextrose broth. Harvested leaves were photographed 2, 4, 6 days after inoculation and the diameters of lesion size were determined by Image $\mathrm{J}$ 
software in randomly selected areas of taken pictures. Data were acquired from four independent experiments (20 plants of per replicate) and 25 leaves were selected for each replicate. Analysis of variance was performed using statistix version 8.0 (Analytical Software, Tallahassee, FL, USA). Leave and flower samples from 10 transgenic plants were collected for AcCP2 protein detection, when were flowering.

\subsection{Bioinformatic Analysis}

Similarity search of the $A c C P 2$ sequence in public nucleotide or protein databases was performed using Blastn or Blastx algorithms [51]. The conserved domains were analyzed by online alignment [52]. A phylogenetic tree was constructed by the neighbor-joining (NJ) method using the $\mathrm{NJ}$ algorithm implemented in the Molecular Evolutionary Genetics Analysis (MEGA) software version 4.0.

For constructing three dimensional (3D) structure of AcCP2, a template for homology modeling was searched with BLAST program on Protein Data Bank [53,54]. Model was constructed in light of the root mean square deviation of $\mathrm{C}_{\alpha}$ atoms between the modeled structure and the template structure within a reasonable range [9]. The consistency and viability of protein structure were evaluated and validated by PROCHECK software available online [55].

\section{Conclusions}

In our study, AcCP2 belonging to the CA1 subfamily was isolated from pineapple fruit. The functional domains were analyzed based on the molecular modeling and homology alignment. Transcripts of $A c C P 2$ gradually increased during fruit development until maturity. The pPIC9K-His$A c C P 2$ recombinant was overexpressed in P. pastoris. The purified AcCP2 protein can be processed to a $25 \mathrm{kDa}$ mature form after acid treatment $(\mathrm{pH} 4.3)$ in vitro. Optimum proteolytic specificity to Bz-Phe-Val-Arg-NH-Mec was showed at neutral. In additon, AcCP2 expressed in Arabidopsis plants can also improve its resistance to fungal pathogens. This implies that $A c C P 2$ could take part in fruit development and resistance responses.

\section{Supplementary Materials}

Supplementary materials can be accessed at: http://www.mdpi.com/10.3390/19/2/2374/s1.

\section{Acknowledgments}

This research was supported by grants from by the Hainan Natural Science Fund of China (313055), Special Fund for Agro-scientific Research in the Public Interest (3-41), and Fund on Basic Scientific Research Project of Nonprofit Central Research Institutions (200701).

\section{Author Contributions}

Conception and design: Wei Wang, Lu Zhang, Ning Guo and Jianghui Xie; Provision of study materials and technology: Wei Wang, Lu Zhang, Ning Guo, Xiumei Zhang, Chen Zhang, Guangming Sun and Jianghui Xie; Data analysis and interpretation: Wei Wang, Lu Zhang, Ning Guo, Chen Zhang, Guangming Sun and Jianghui Xie; Manuscript writing: Wei Wang, Lu Zhang and Jianghui Xie; Final 
approval of manuscript: Wei Wang, Lu Zhang, Ning Guo, Xiumei Zhang, Chen Zhang, Guangming Sun and Jianghui Xie.

\section{Conflicts of Interest}

The authors declare no conflict of interest.

\section{References}

1. Solomon, M.; Belenghi, B.; Delledonne, M.; Menachem, E.; Levine, A. The involvement of cysteine proteases and protease inhibitor genes in the regulation of programmed cell death in plants. Plant Cell 1999, 11, 431-444.

2. Krüger, J.; Thomas, C.M.; Golstein, C.; Dixon, M.S.; Smoker M.; Tang, S.J.; Mulder, L.; Jones, J.D.G. A tomato cysteine protease required for Cf-2-dependent disease resistance and suppression of autonecrosis. Science 2002, 296, 744-747.

3. Alonso, J.M.; Granell, A. A putative vacuolar processing protease is regulated by ethylene and also during fruit ripening in citrus fruit. Plant Physiol. 1995, 109, 541-547.

4. Mohan, S.; Ma, P.W.K.; Williams, W.P.; Luthe, D.S. A naturally occurring plant cysteine protease possesses remarkable toxicity against insect pests and synergizes Bacillus thuringiensis toxin. PLoS One 2008, 3, e1786.

5. Bozhkov, P.V.; Suarez, M.F.; Filonova, L.H.; Daniel, G.; Zamyatnin, A.A.; Rodriguez-Nieto, S.; Zhivotovsky, B.; Smertenko, A. Cysteine protease mcII-Pa executes programmed cell death during plant embryogenesis. Proc. Natl. Acad. Sci. USA 2005, 102, 14463-14468.

6. Toyooka, K.; Okamoto, T.; Minamikawa, T. Mass transport of proform of a KDEL-tailed cysteine proteinase (SH-EP) to protein storage vacuoles by endoplasmic reticulum-derived vesicle is involved in protein mobilization in germinating seeds. J. Cell Boil. 2000, 148, 453-463.

7. Souza, D.P.; Freitas, C.D.T.; Pereira, D.A.; Nogueira, F.C., Silva, F.D.A.; Salas, C.E.; Ramos, M.V. Laticifer proteins play a defensive role against hemibiotrophic and necrotrophic phytopathogens. Planta 2011, 234, 183-193.

8. MEROPS the Peptidase Database. Available online: http://merops.sanger.ac.uk/ (accessed on 12 October 2013).

9. Trejo, S.A.; López, L.M.I.; Caffini, N.O.; Natalucci, C.L.; Canals, F.; Avilés, F.X. Sequencing and characterization of asclepain $\mathrm{f}$ : The first cysteine peptidase cDNA cloned and expressed from Asclepias. fruticosa latex. Planta 2009, 230, 319-328.

10. Drenth, J.; Jansoniu, J.N.; Koekoek, R.; Swen, H.M.; Wolthers, B.G. Structure of papain. Nature 1968, 218, 929-932.

11. Rawlings, N.D.; Barrett, A.J.; Bateman, A. MEROPS: The database of proteolytic enzymes, their substrates and inhibitors. Nucleic Acids Res. 2012, 40, D343-D350.

12. Wiederanders, B.; Kaulmann, G.; Schilling, K. Functions of propeptide parts in cysteine proteases. Curr. Protein Pept. Sci. 2003, 4, 309-326.

13. Van der Hoorn, R.A.L. Plant proteases: From phenotypes to molecular mechanisms. Annu. Rev. Plant Biol. 2008, 59, 191-223. 
14. Oliveira, A.S.; Filho, J.X.; Sales, M.P. Cysteine proteinases cystatins. Braz. Arch. Biol. Techn. 2003, 46, 91-104.

15. Gautam, S.S.; Mishra, S.K.; Dash, V.; Goyal, A.K.; Rath, G. Comparative study of extraction, purification and estimation of bromelain from stem and fruit of pineapple plant. Thai J. Pharm. Sci. 2010, 34, 67-76.

16. Larocca, M.; Rossano, R.; Santamaria, M.; Riccio, P. Analysis of pineapple [Ananas comosus (L.) Merr.] fruit proteinases by 2-D zymography and direct identification of the major zymographic spots by mass spectrometry. Food Chem. 2010, 123, 1334-1342.

17. Maurer, H.R. Bromelain: Biochemistry, pharmacology and medical use. Cell Mol. Life Sci. 2001, $58,1234-1245$.

18. Harrach, T.; Eckert, K.; Schulze-Forster, K.; Nuck, R.; Grunow, D.; Maurer, H.R. Isolation and partial characterization of basic proteinases from stem bromelain. J. Protein Chem. 1995, 14, 41-52.

19. Rowan, A.D.; Buttle, D.J.; Barrett, A.J. The cysteine proteases of the pineapple plant. Biochem. J. 1990, 266, 869-875.

20. Hale, L.P.; Greer, P.K.; Trinh, C.T.; James, C.L. Proteinase activity and stability of natural bromelain preparations. Int. Immunopharmacol. 2005, 5, 783-793.

21. Yamada, F.; Takahashi, N.; Murachi, T. Purification and characterization of a protease from pineapple fruit, fruit bromelain FA2. J. Biochem. 1976, 79, 1223-1234.

22. Corzo, C.A.; Waliszewski, K.N.; Welti-Chanes, J. Pineapple fruit bromelain affinity to different protein substrates. Food Chem. 2012, 133, 631-635.

23. Ritonja, A.; Rowan, AD.; Buttle, D.J.; Rawlings, N.D.; Turk, V.; Barrett, A.J. Stem bromelain: Amino acid sequence and implications for weak binding of cystatin. Fed. Eur. Biochem. Soc. Lett. 1989, 247, 419-424

24. Amid, A.; Ismail, N.A.; Yusof, F.; Salleh, H.M. Expression, purification, and characterization of a recombinant stem bromelain from Ananas comosus. Process Biochem. 2011, 46, 2232-2239.

25. Aoki, H.; Nazmul Ahsan, M.; Watabe, S. Heterologous expression in Pichia pastoris and single-step purification of a cysteine proteinase from northern shrimp. Protein Expres. Purif. 2003, 31, 213-221.

26. Beers, E.P.; Jones, A.M.; Dickerman, A.W. The S8 serine, C1A cysteine and A1 aspartic protease families in Arabidopsis. Photochemistry 2004, 65, 43-58.

27. Neuteboom, L.W.; Matsumoto, K.O.; Christopher, D.A. An extended AE-rich N-terminal trunk in secreted pineapple cystatin enhances inhibition of fruit bromelain and is posttranslationally removed during ripening. Plant Physiol. 2009, 151, 515-527.

28. Brömme, D.; Nallaseth, F.S.; Turk, B. Production and activation of recombinant papain-like cysteine proteases. Methods 2004, 32, 199-206.

29. Karrer, K.M.; Peiffer, SL.; DiTomas, M.E. Two distinct gene subfamilies within the family of cysteine protease genes. Proc. Natl. Acad. Sci. USA 1993, 90, 3063-3067.

30. Vernet, T.; Berti, P.J.; de Montigny, C.; Musil, R.; Tessier, D.C.; Menard, R.; Magny, M.C.; Storer, A.C.; Thomas, D.Y. Processing of the papain precursor. The ionization state of a conserved amino acid motif within the proregion participates in the regulation of intramolecular processing. J. Biol. Chem. 1995, 270, 10838-10846. 
31. Gomes, M.T.; Teixeira, R.D.; Lopes, M.T.; Nagem, R.A.; Salas, C.E. X-ray crystal structure of CMS1MS2: A high proteolytic activity cysteine proteinase from Carica candamarcensis. Amino Acids 2012, 43, 2381-2391.

32. Barrett, A.J.; Rawlings, N.D. Introduction: The Clans and Families of Cysteine Peptidases. In Handbook of Proteolytic Enzymes, 2nd ed.; Barrett, A.J., Rawlings, N.D., Woessner, J.F., Eds.; Elsevier: London, UK, 2004; pp. 1051-1071.

33. Smooker, P.M.; Whisstock, J.C.; Irving, J.A.; Siyaguna, S.; Spithill, T.W.; Pike, R.N. For the record: A single amino acid substitution affects substrate specificity in cysteine proteinases from Fasciola hepatica. Protein Sci. 2000, 9, 2567-2572.

34. Yamada, T.; Ohta, H.; Shinohara, A.; Iwamatsu, A.; Shimada, H.; Tsuchiya, T.; Masuda, T.; Takamiya, K.I. A cysteine protease from maize isolated in a complex with cystatin. Plant Cell. Physiol. 2000, 41, 185-191.

35. Dahl, S.W.; Halkier, T.; Lauritzen, C.; Dolenc, I.; Pedersen, J.; Turk, V.; Turk, B. Human recombinant pro-dipeptidyl peptidase I (cathepsin $\mathrm{C}$ ) can be activated by cathepsins $\mathrm{L}$ and $\mathrm{S}$ but not by autocatalytic processing. Biochemistry 2001, 40, 1671-1678.

36. Koia, J.H.; Moyle, R.L.; Botella, J.R. Microarray analysis of gene expression profiles in ripening pineapple fruits. BMC Plant Biol. 2012, 12, 240.

37. Ariizumi, T.; Higuchi, K.; Arakaki, S.; Sano, T.; Asamizu, E.; Ezura, H. Genetic suppression analysis in novel vacuolar processing enzymes reveals their roles in controlling sugar accumulation in tomato fruits. J. Exp. Bot. 2011, 62, 2773-2786.

38. Zhang, X.M.; Wang, W.; Du, L.Q.; Xie, J.H.; Yao, Y.L.; Sun, G.M. Expression patterns, activities and carbohydrate-metabolizing regulation of sucrose phosphate synthase, sucrose synthase and neutral invertase in pineapple fruit during development and ripening. Int. J. Mol. Sci. 2012, 13, 9460-9477.

39. Matarasso, N.; Schuster, S.; Avni, A. A novel plant cysteine protease has a dual function as a regulator of 1-aminocyclopropane-1-carboxylic acid synthase gene expression. Plant Cell 2005, 17, 1205-1216.

40. Yamada, K.; Shimada, T.; Nishimura, M.; Hara-Nishimura, I. A VPE family supporting various vacuolar functions in plants. Physiol. Plant 2005, 123, 369-375.

41. Konno, K.; Hirayama, C.; Nakamura, M.; Tateishi, K.; Tamura, Y.; Hattori, M.; Kohno, K. Papain protects papaya trees from herbivorous insects: Role of cysteine proteases in latex. Plant J. 2004, 37, 370-378.

42. López, L.; Camas, A.; Shivaji, R.; Ankala, A.; Williams, W.P.; Luthe, D.S. Mir1-CP, a novel defense cysteine protease accumulates in maize vascular tissues in response to herbivory. Planta 2007, 226, 517-527.

43. Raimbault, A.K.; Zuily-Fodil, Y.; Soler, A.; Mora, P.; de Carvalho, C.M.H. The expression patterns of bromelain and AcCYS1 correlate with blackheart resistance in pineapple fruits submitted to postharvest chilling stress. J. Plant Physiol. 2013, 170, 1442-1446.

44. Jung, Y.J.; Choi, C.S.; Park, J.H.; Kang, H.W.; Choi, J.E.; Nou, I.S.; Lee, S.Y.; Kang, K.K. Overexpression of the pineapple fruit bromelain gene $(B A A)$ in transgenic Chinese cabbage (Brassica rapa) results in enhanced resistance to bacterial soft rot. Electron J. Biotech. 2008, 11, $1-9$. 
45. López-García, B.; Hernandez, M.; Segundo, B.S. Bromelain, a cysteine protease from pineapple (Ananas comosus) stem, is an inhibitor of fungal plant pathogens. Lett. Appl. Microbial. 2012, 55, $62-67$.

46. Nieuwenhuizen, N.J.; Maddumage, R.; Tsang, G.K.; Fraser, L.G.; Cooney, J.M.; de Silva, H.N.; Green, S.; Richardson, K.A. Atkinson R.G. Mapping, complementation, and targets of the cysteine protease actinidin in kiwifruit. Plant Physiol. 2012, 158, 376-388.

47. Zhang, X.; Henriques, R.; Lin, S.S.; Niu, Q.W.; Chua, N.H. Agrobacterium-mediated transformation of Arabidopsis thaliana using the floral dip method. Nat. Protoc. 2006, 1, 641-646.

48. Candiano, G.; Bruschi, M.; Musante, L.; Santucci, L.; Ghiggeri, G.M.; Carnemolla, B.; Orecchia, P.; Zardi, L.; Righetti, P.G. Blue silver: A very sensitive colloidal Coomassie G-250 staining for proteome analysis. Electrophoresis 2004, 25, 1327-1333.

49. Nagarathnam, R.; Rengasamy, A.; Balasubramanian, R. Purification and properties of cysteine protease from rhizomes of Curcuma longa (Linn.). J. Sci. Food Agric. 2010, 90, 97-105.

50. Stewart, C.N.; Via, L.E. A rapid CTAB DNA isolation technique useful for RAPD fingerprinting and other PCR applications. Biotechniques 1993, 14, 748-750.

51. Blast. Available online: http://blast.ncbi.nlm.nih.gov/Blast.cgi (accessed on 20 March 2012).

52. NCBI. Available online: http://www.ncbi.nlm.nih.gov/Structure/cdd/wrpsb.cgi (accessed on 20 March 2012).

53. Berman, H.M.; Westbrook, J.; Feng, Z.; Gilliland, G.; Bhat, T.N.; Wessig, H.; Shindyalov, N.; Bourne, P.E. The protein data bank. Nucleic Acids Res. 2000, 28, 235-242.

54. Biological Macromolecular Resource. Available online: http://www.rcsb.org/pdb/ (accessed on 10 December 2012).

55. PROCHECK. Available online: http://www.ebi.ac.uk/thornton-srv/software/PROCHECK/ download.html (accessed on 10 December 2012).

Sample Availability: Samples of the compounds Fruit proteinases, Z-Arg-Arg-NH-Mec and Bz-Phe-Val-Arg-NH-Mec are available from the authors.

(C) 2014 by the authors; licensee MDPI, Basel, Switzerland. This article is an open access article distributed under the terms and conditions of the Creative Commons Attribution license (http://creativecommons.org/licenses/by/3.0/). 